\title{
走进臭豆腐的化学世界
}

李夏蕾, 赖勇杰, 李荀 ${ }^{*}$

教育部天然产物与化学生物学重点实验室, 山东大学药学院, 济南 250012

摘要: 从化学的角度, 对中华风味小吃臭豆腐制作工艺中涉及的化学原理进行科普, 同时还介绍了其对人体健康的 利弊, 旨在丰富读者对这一中华传统小吃的科学认知。

关键词：臭豆腐; 制作工艺; 化学原理; 美拉德反应

中图分类号: G64; 06

\section{Entering the Chemistry World of Fermented Stinky Tofu}

\section{Xialei Li, Yongjie Lai, Xun Li *}

Key Laboratory of Chemical Biology (Ministry of Education), School of Pharmaceutical Sciences, Shandong University, Jinan 250012, P. R. China.

Abstract: From the perspective of chemistry, this paper popularized the chemical principles of processing fermented stinky tofu, and also introduced the potential influences on human health, aiming to enriching the scientific understanding of this Chinese-flavored traditional snack to readers.

Key Words: Fermented stinky tofu (FST); Productive process; Chemical principles; Maillard reaction

作为中华传统美食之一的臭豆腐, 以其墨黑之色、醇香之味、酥嫩之感而颇负盛名, 深受食客 们的喜爱。这其中又以老北京的王致和臭豆腐乳和长沙的油炸臭豆腐干最为出名, 二者的制作工艺 有异曲同工之妙。本文主要从臭豆腐制作工艺中涉及的化学原理及其对人体健康的利弊做一科普, 旨在丰富读者对这一中华传统小吃的科学认知。

\section{1 臭豆腐的历史起源}

相传清康熙年间, 安徽考生王致和多次赴京赶考均金榜落第, 无奈只得以卖豆腐暂谋生计。但 遇夏日炎炎时, 豆腐很快会发霉而无法食用。为了不浪费血汗, 王致和苦思良久, 决定将豆腐切成 小块, 稍加晾晒, 放入缸中以盐和花椒等作料腌制保存。一段时间后打开缸盖, 发现豆腐已变成青 灰色并伴着刺鼻臭气。他试探性尝了一口, 发现臭气之余竟蕴含着浓郁之香。后经他多次改良配方, 终使臭豆腐声名远扬, 连清朝状元孙家蒻也为臭豆腐亲题藏头诗一首 “致君美味传千里, 和我天机 养寸心, 酱配龙蟠调药药, 园开鸡跖钟芙蓉” 。相传臭豆腐还被慈禧太后钦点为御熷小菜, 并赐名 “青方”，后人一直沿用至今。

收稿: 2019-07-28; 录用: 2019-08-22; 网络发表: 2019-09-20 


\section{2 臭豆腐制作工艺中的化学原理}

\section{1 制作臭卤水}

臭卤水是制作臭豆腐的关键原料。将豆豉入冷水锅, 烧开后煮约三十分钟, 滤出豆汁, 冷却后 加入碳酸钠、硫酸亚铁、蔬菜和调味品, 浸泡十五天左右, 即制得臭卤水。Liu 等 ${ }^{[1]}$ 利用固相微萃取-气 相色谱/质谱(Solid Phase Microextraction-Gas Chromatography/Mass Spectrometer,SPME-GC/MS)技术， 在臭卤水中检出了包括酯、醇、烯烃、硫化物、杂环化合物、羧酸、酮、醛、苯酚、胺和醚在内的 39 种挥发性有机物。其中, 苯酚因其具有特殊香气, 能对臭豆腐的气味起到稳定效果。不仅如此, 酚羟基易被氧化成醌, 加上其捕获自由基的能力, 由此表现出较强的抗氧化活性, 可起到杀菌消毒 的作用。臭卤水中的 3-甲基吲哚是一种具有强烈臭味的物质, 又称粪臭素, 是臭豆腐具有特殊臭味 的关键 ${ }^{[2]}$ 。由于机体生命活动所必需的色氨酸中就有吲哚结构, 由此 Chao 等 ${ }^{[3]}$ 推测豆腐中的蛋白质 在微生物和有关酶的作用下发酵产生色氨酸, 进一步降解为 3-甲基吲哚。 $\mathrm{Ye}^{\text {等 }}{ }^{[4]}$ 对比了臭豆腐和臭 卤水中所含的生物胺, 发现臭卤水中主要含腐胺、尸胺和亚精胺; 而臭豆腐中除了这三种胺, 还含 有精胺和胍丁胺。总之, 不同产地臭豆腐的独特风味主要归功于各自卤水配方中挥发性有机物含量 的差异。

\section{2 制作豆腐胚子}

豆腐的制作原料是富含蛋白质的黄豆。将洗净泡发好的黄豆加水磨成糊，装入布袋滤出浆液。 浆液煮沸后, 在搅拌过程中点卤, 随后静置一段时间, 自然沉降后即成豆腐脑, 进一步压去水分制 得豆腐胚子。点卤步骤属于典型的胶体聚沉现象。传统卤水的主要成分是氯化镁和硫酸钙, 这些强 电解质中的正负离子与水分子吸引, 破坏了蛋白质表面的水化层, 同时也中和了相斥的电荷, 使分 散的蛋白质颗粒得以凝聚形成大胶粒而沉降出来 ${ }^{[5]}$ 。由于传统卤水豆腐略带苦涩味, 目前有用凝固 剂葡萄糖酸内酯来替代卤水。葡萄糖酸内酯经水解作用形成葡萄糖酸, 使体系处于酸性环境, 一些 对酸较为敏感的蛋白质易变性凝固。由于内酯水解速度较为缓慢, 凝固反应均匀一致, 出品率高, 且细淢无异味, 已被逐步推广使用。

\section{3 晾晒发酵}

豆腐成型后置于阴凉通风处进行为期 5-7 天的首次发酵, 以豆腐块表面长满白色菌毛为好, 发 酵时间过长则会产生大量对人体有害的生物胺 ${ }^{[4]}$ 。将发酵好的腐乳胚经搓毛处理后分层次码放入缸 或坛中, 再放入盐和花椒等作料, 于室温下腌渍 7 天左右。此后用石灰泥密封坛口, 于 $30-40{ }^{\circ} \mathrm{C}$ 下 进行二次发酵, 数月后成为臭豆腐, 即北方人常吃的腐乳。

\section{4 油炸臭豆腐中的化学反应}

南方人常吃的油炸臭豆腐则是将豆腐坏子冷透后浸入臭卤水中, 每次浸卤时间为 3-4h, 连续浸 过 2-3 次后, 将成品洗净油炸后食用。油炸条件下, 臭豆腐中的一些不饱和脂肪酸和中级醛会发生 不同程度的氧化生成低级醛, 使豆腐产生特殊的油脂香味。此外, 臭豆腐中的杂环化合物吡嗪、吡 啶、呋喃酮等在高温下可以和豆腐中其他成分反应生成一些具有焦糖和烘烤香味的物质。郑兵福 等 ${ }^{[6]}$ 通过检测油炸臭豆腐中的挥发性成分, 发现其烷烯炔和醇酚醚等成分的相对含量均发生了不同 程度的改变。此外, 臭豆腐中的醛、酮、生物胺、氨基酸等物质高温下易发生羰氨缩合反应, 即美 拉德反应(Maillard reaction), 生成颜色加深的物质, 并赋予食品一定的风味 ${ }^{[7]}$ 。同时还伴有斯特勒克 降解反应(Strecker reaction), 该反应由含有活泼亚甲基的邻二羰基化合物与氨基酸反应, 生成二氧化 碳和邻氨基醛, 副产物为吡嗪类物质 ${ }^{[8]}$, 也能够促进食品风味形成。由此可见, 油炸能在很大程度上 改善臭豆腐中的风味成分, 还能除去浸泡臭卤时所带来的有害物质。

\section{3 臭豆腐对人体健康的利与弊}

\section{1 营养价值}

臭豆腐属于发酵豆制品，而豆制品最大的营养价值在于其所含有的丰富植物性蛋白和钙元素。 
植物蛋白可在体内各种酶的催化下分解为人体所需的多种氨基酸。而钲元素不仅能有效缓解骨质疏 松等症状, 还能减少体内铝元素的蓄积, 降低体内胆固醇水平, 很好地预防高血压等心血管疾病 ${ }^{[9]}$ 。 而发酵后豆腐所含的蛋白质和钻元素更易被机体吸收, 类似于国外的奶酪和纳豆等发酵食品, 因此 国外人更喜欢把臭豆腐称作 “中国奶酪(Chinese cheese)”。不仅如此, 豆腐经发酵后最显著的益处 在于其在微生物作用下生成大量维生素 $\mathrm{B}_{12}$, 每 $100 \mathrm{~g}$ 臭豆腐中就有 5-10 mg 维生素 $\mathrm{B}_{12}$, 每天吃半 块臭豆腐所带来的维生素 $\mathrm{B}_{12}$ 就可显著预防老年性痴呆 ${ }^{[10]}$ 。维生素 $\mathrm{B}_{12}$ 还可通过参与机体 DNA 的合 成、修饰等过程, 降低患肿瘤的几率和风险, 尤其是血液瘤 ${ }^{[11]}$, 且臭豆腐中不含胆固醇, 这是其他 植物性食品所不能比拟的。

事实上, 卤水中的有些成分对健康也是大有裨益的。卤水中的美元素能强健骨骼和牙齿、有效 预防心血管疾病 ${ }^{[12]}$ 。卤水中的硫酸亚铁与某些发酵物反应后生成墨绿色的硫化铁, 使臭豆腐呈现一 种特殊的墨黑色。然而, 硫酸亚铁毕竟是金属制剂, 不能过多使用, 现在人们多用茶叶来替代硫酸 亚铁。茶叶中茶多酚对食品上色起了关键作用, 通过酚羟基与金属离子发生络合反应生成有颜色的 配合物, 可使臭豆腐呈现与硫酸亚铁类似的颜色。由于茶多酚还具有抗氧化、抗衰老、降血脂、降 血糖、抑菌消炎、抗癌等多种生理活性, 故使用茶叶上色比硫酸亚铁更为安全和健康 ${ }^{[13]}$ 。

\section{2 潜在的健康危害}

首先, 臭豆腐盐分含量高, 因而不适合高血压、冠心病、动脉硬化等患者食用。其次, 臭豆腐 中的生物胺可与亚硝酸盐反应生成有致癌作用的亚硝胺, 因此在吃臭豆腐的同时应多吃新鲜蔬菜和 水果, 其所富含的维生素 $\mathrm{C}$ 可有效阻断亚硝胺的生成。最后, 臭豆腐在发酵时会产生一种叫 “肉毒 梭菌” 的毒素, 这是毒性最强的蛋白质之一。若大量食入, 会出现头晕、呼吸困难、肌肉乏力等中 毒症状。因此, 对于 “闻着臭而吃着香”的臭豆腐, 正规厂家生产的完全可放心食用, 但要适当控制 每日的食用量。

\section{4 结语}

作为中华美食文化的传统代表, 臭豆腐的历史源远流长。本文以通俗易懂的语言为广大读者科 普了臭豆腐的制作工序, 这其中所包含的化学原理, 值得我们思考。例如, 吲哚类和硫醚类物质在 臭卤水风味的形成中大放异彩, 美拉德反应又为最终成品注入灵魂等。本文最后介绍了臭豆腐对人 体健康的利弊，并对臭豆腐的食用量提出了合理建议。

\section{参 考 文 献}

[1] Liu, Y. P.; Miao, Z. W.; Guan, W.; Sun, B. G. Molecules 2012, 17 (4), 3708.

[2] 唐辉, 陈霖, 曾玉伦, 李跑, 贺静, 蒋立文. 南方农业学报, 2019, 50 (4), 831.

[3] Chao, S. H.; Tomii, Y.; Sasamoto, M.; Fujimoto, J.; Tsai, Y. C.; Watanabe, K. Int. J. Syst. Evol. Micr. 2008, 58 (Pt 11), 2555.

[4] Liu, Z. F.; Wei, Y. X.; Zhang, J. J.; Liu, D. H.; Hu, Y. Q.; Ye, X. Q. Int. J. Food Sci. Tech. 2011, 46 (4), 687.

[5] 李红, 秦芗, 黎恒. 农村经济与科技, 2017, 28 (7), 67.

[6] 郑兵福, 徐睿烜, 蒋立文. 中国酿造, 2019, 38 (3), 14.

[7] 郑文华, 许旭. 化学进展, 2005, 17 (1), 123.

[8] Ezzatzadeh, E.; Hossaini, Z. Nat. Prod. Res. 2018, 1.

[9] 刘琪, 曾玉伦, 蒋立文, 廖卢艳, 李跑, 陈录芬. 食品安全质量检测学报, 2018, 9 (6), 1421.

[10] Miles, L. M.; Allen, E.; Clarke, R.; Mills, K.; Uauy, R.; Dangour, A. D. Eur. J. Clin. Nutr. 2017, 71 (10), 1166.

[11] Romain, M.; Sviri, S.; Linton, D. M.; Stav, I.; van Heerden, P. V. Anaesth Intensive Care. 2016, 44 (4), 4472.

[12] Leenders, N. H. J.; Vervloet, M. G. Nutrients 2019, 11 (2), 455.

[13] Prasanth, M. I.; Sivamaruthi, B. S.; Chaiyasut, C.; Tencomnao, T. Nutrients 2019, 11 (2), 474. 